\title{
NIPT-based screening for Down syndrome and beyond: what do pregnant women think?
}

Citation for published version (APA):

van Schendel, R. V., Dondorp, W. J., Timmermans, D. R. M., van Hugte, E. J. H., de Boer, A., Pajkrt, E., Lachmeijer, A. M. A., \& Henneman, L. (2015). NIPT-based screening for Down syndrome and beyond: what do pregnant women think? Prenatal Diagnosis, 35(6), 598-604. https://doi.org/10.1002/pd.4579

Document status and date:

Published: 01/01/2015

DOI:

10.1002/pd.4579

Document Version:

Publisher's PDF, also known as Version of record

Document license:

Taverne

Please check the document version of this publication:

- A submitted manuscript is the version of the article upon submission and before peer-review. There can be important differences between the submitted version and the official published version of record.

People interested in the research are advised to contact the author for the final version of the publication, or visit the DOI to the publisher's website.

- The final author version and the galley proof are versions of the publication after peer review.

- The final published version features the final layout of the paper including the volume, issue and page numbers.

Link to publication

\footnotetext{
General rights rights.

- You may freely distribute the URL identifying the publication in the public portal. please follow below link for the End User Agreement:

www.umlib.nl/taverne-license

Take down policy

If you believe that this document breaches copyright please contact us at:

repository@maastrichtuniversity.nl

providing details and we will investigate your claim.
}

Copyright and moral rights for the publications made accessible in the public portal are retained by the authors and/or other copyright owners and it is a condition of accessing publications that users recognise and abide by the legal requirements associated with these

- Users may download and print one copy of any publication from the public portal for the purpose of private study or research.

- You may not further distribute the material or use it for any profit-making activity or commercial gain

If the publication is distributed under the terms of Article $25 \mathrm{fa}$ of the Dutch Copyright Act, indicated by the "Taverne" license above, 


\section{Next-generation decisions empowered by next-generation technology}

\section{When accuracy matters-reproductive genetic testing with Ion Torrent NGS solutions}

Next-generation sequencing (NGS) technology is revolutionizing reproductive research with fast, accurate, and comprehensive detection of a broad spectrum of genetic variants found to cause inherited disorders.

Labs implementing NGS for inherited disease research are expanding the ability of the scientific community to identify and understand life-altering genetic variants.

How can you make an impact? Learn more about expanded carrier-screening research and preimplantation genetic testing with lon Torrent ${ }^{\text {TM }}$ NGS technology including the lon GeneStudio"m S5 System.

- Sample-to-result workflows

- Intuitive data analysis

- Accessibility, regardless of technical or bioinformatics experience

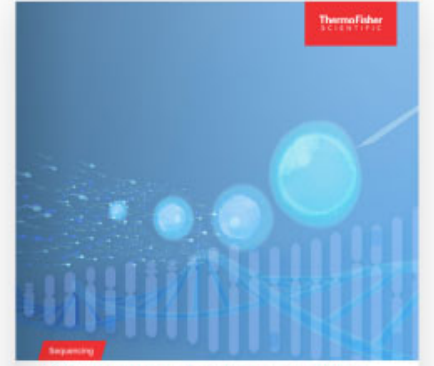

Next-generation decisions empowered by next-generation technologies Reproductive gonetic testing
with lon Torent NGS soutione
" $80 \%$ of parents with a child born with a recessive disorder are not aware of a family history of that condition." Learn more in this brochure. 


\title{
NIPT-based screening for Down syndrome and beyond: what do pregnant women think?
}

\author{
Rachèl V. van Schendel ${ }^{1,2 *}$, Wybo J. Dondorp ${ }^{3}$, Danielle R. M. Timmermans ${ }^{2,4}$, Eline J. H. van Hugte ${ }^{1,2}$, Anne de Boer ${ }^{1,2}$, Eva Pajkrt ${ }^{5}$, \\ Augusta M. A. Lachmeijer ${ }^{1}$ and Lidewii Henneman ${ }^{1,2}$ \\ ${ }^{1}$ Department of Clinical Genetics, VU University Medical Center, Amsterdam, the Netherlands \\ 2EMGO Institute for Health and Care Research, VU University Medical Center, Amsterdam, the Netherlands \\ ${ }^{3}$ Department of Health, Ethics and Society, Faculty of Health, Medicine and Life Sciences, Research Institutes GROW and CAPHRI, Maastricht University, \\ Maastricht, the Netherlands \\ ${ }^{4}$ Department of Public and Occupational Health, VU University Medical Center, Amsterdam, the Netherlands \\ ${ }^{5}$ Department of Obstetrics and Gynecology, Fetal Medicine Unit, Academic Medical Center, Amsterdam, the Netherlands \\ *Correspondence to: Rachèl van Schendel. E-mail: r.schendel@vumc.nl
}

\begin{abstract}
Objective The aim of the study is to study pregnant women's views on noninvasive prenatal testing (NIPT) for Down syndrome and the potential to test for a broader range of conditions.

Methods An online questionnaire available on the Dutch pregnancy fair website was completed by 381 pregnant women.

Results Of the women, 51\% expressed interest in having NIPT, including 33\% of women who had declined first-trimester screening. The majority (73\%) thought that the uptake of screening would increase with NIPT. Most women agreed that testing for life-threatening (89\%), severe physical (79\%), or severe mental (76\%) disorders should be offered. A minority (29\%) felt that prenatal screening should also be offered for late-onset disorders. Most (41\%) preferred to have a free choice from a list of disorders, $31 \%$ preferred a 'closed offer', and $26 \%$ preferred choosing between packages of disorders. Although most women $(76 \%)$ thought that screening for a broad range of conditions would avoid much suffering, 39\% feared that it would confront couples with choices, the implications of which would be difficult to grasp.
\end{abstract}

Conclusion The results suggest that the uptake of screening will increase with NIPT. If NIPT will be offered for a broad range of conditions, it is crucial to find a way that facilitates rather than undermines well-informed decision-making. (c) 2015 John Wiley \& Sons, Ltd.

Funding sources: The study was funded by the Netherlands Organization for Health Research and Development (ZonMw, grant no: 209020003), as part of the Regional Perinatal Network Northwest Netherlands, and is also part of the research program of the CSG Centre for Society and the Life Sciences, funded by the Netherlands Genomics Initiative.

Conflicts of interest: None declared

\section{INTRODUCTION}

Over the last few years, a vast amount of research and opinion papers have been published on the introduction and evaluation of noninvasive prenatal testing (NIPT) for fetal aneuploidies. With NIPT, a blood sample of the mother is drawn to determine whether a normal or abnormal quantity of fetal DNA from chromosome 21, 18, or 13 is present in the maternal plasma. ${ }^{1}$ NIPT has a high sensitivity and specificity, can be performed from 7 weeks of gestation onwards, and poses no miscarriage risk. Studies performed among pregnant women and their partners have shown that these benefits make NIPT a preferred alternative to risky and stressful invasive procedures and to the less accurate first-trimester screening. ${ }^{2-6}$ Although NIPT offers clear advantages over conventional prenatal tests, women have also expressed uneasiness about its use. Concerns that prenatal testing could become routinized and women might feel pressured to accept NIPT because it is uncomplicated and free of risk were raised. ${ }^{5,6}$ Moreover, worries were conveyed about potential stigmatization of children and adults with a disability. ${ }^{5,6}$ The latter concern is fundamental as NIPT is an emerging technology already expanding its use to test for more disorders than just fetal aneuploidies. At present, NIPT is applied to determine fetal sex in order to identify X-linked disorders and to determine fetal Rhesus $\mathrm{D}$ genotype in Rhesus $\mathrm{D}$ negative mothers. ${ }^{7}$ However, NIPT has even more potential as it has been demonstrated that the entire fetal genome is represented in the maternal plasma, ${ }^{8,9}$ making it possible to diagnose an increasing number of disorders. NIPT for several single-gene disorders is already feasible, especially in conditions where a 
single mutation accounts for the majority of cases, such as achondroplasia. $^{10}$ Moreover, an increasing number of commercial companies are expanding their NIPT offer to include (optional) screening for microdeletion syndromes and large duplications, although some commentators have called for caution. ${ }^{11}$

In the long run, it is expected that NIPT will also be deployed to detect fetomaternal risk factors (i.e. markers for preeclampsia or preterm birth), thus enabling adapted monitoring of a pregnancy. ${ }^{12}$

In the light of these developments, the question arises as to what the scope of NIPT-based prenatal screening should be. Should it include all conditions that can be tested for, or should it consist of a more limited offer? A recent study showed that most women with an increased risk for aneuploidies choose a follow-up test that offers the most information about their child (i.e. a high-resolution genomic array including genetic variants associated with susceptibility of disease). ${ }^{13}$ Moreover, hypothetical interest in testing for several conditions (e.g. cancer susceptibility and childhood-onset and adult-onset disorders) among pregnant women increased when NIPT could be used instead of invasive diagnostic procedures. ${ }^{14}$ On the one hand, it seems that widening the scope of NIPT is in line with the aim of prenatal screening, namely facilitating autonomous reproductive choices, whereas setting limits would raise the specter of paternalism. On the other hand, pretest information about the specifics of all conditions included in broad-scope screening may lead to information overload and thus undermine reproductive decision-making. ${ }^{15}$

Although something is known about pregnant women's interest in testing for broader range of conditions, ${ }^{13-15}$ less is known about women's views on the preferred scope of NIPTbased screening and how it should be offered. This study therefore aims to identify pregnant women's attitudes toward NIPT both for common autosomal aneuploidies and for a potentially much broader range of conditions. The study will focus on understanding pregnant women's views on the following: (1) NIPT-based Down syndrome screening and its implications, (2) conditions for which NIPT-based screening should be available and possible consequences, and (3) who should decide for which conditions NIPT becomes available and, once determined, if it should be offered as a closed offer, in packages, or as a free choice.

This study was performed in the Netherlands, where the uptake of the first-trimester combined test is around $27 \%{ }^{16}$ During the period of the study, NIPT was not yet available in the Netherlands. Shortly after our data were collected, NIPT became available for women at high risk $(\geq 1: 200)$ based on the first-trimester screening, as part of a national implementation research study (Trial by Dutch laboratories for Evaluation of Non-Invasive Prenatal Testing (TRIDENT) study). ${ }^{17}$

\section{METHODS}

A quantitative study, using an online questionnaire, was conducted between January 2014 and March 2014. Ethical approval was granted by the Medical Ethical Committee of the VU University Medical Center Amsterdam (2012.106).

\section{Participants and procedure}

A banner with a link to the questionnaire was placed on the website of the Dutch 'Nine Months Fair'. This is the biggest pregnancy fair in the Netherlands, which is held once a year and has around 52000 annual visitors. Website visitors were invited to complete the questionnaire about 'a new prenatal test during pregnancy', which took about $10 \mathrm{~min}$ to complete. Being pregnant was the only criterion to take part in the study. Women who participated had a chance of winning a $€ 25$ gift voucher.

\section{Survey instrument}

The questionnaire was specifically developed for this study. In the first section, respondents were given a description of the prenatal screening program in the Netherlands (i.e. firsttrimester screening, possibly followed by chorionic villus sampling or amniocentesis), followed by a question delineating whether the respondent had had any of the available tests in a previous or the current pregnancy or was planning to do so. A brief explanation was given about NIPT: test procedure (blood sample of mother), conditions included (trisomies 21, 13, and 18), test accuracy ( $>99 \%$ for trisomy 21 ), timing ( $>9$ weeks), and need for follow-up testing to confirm positive NIPT result. Moreover, it was mentioned that NIPT will likely replace the current first-trimester screening test. Intention to have NIPT was measured with a single item: 'If NIPT was available in the Netherlands, would you choose this test in this or a next pregnancy?' (answer options: 'most certainly yes'; 'probably yes'; 'maybe yes, maybe not'; 'probably not'; 'most certainly not'). Women were also asked what they were willing to pay for NIPT [answer options: 'nothing'; 'the same as for the firsttrimester screening ( $€ 150$ )'; ‘ $€ 250$ '; ‘ $€ 350$ '; ‘ $€ 450$ '; ‘ $€ 550$ or more’].

Specific questions assessed respondents' views on NIPTbased screening for Down syndrome and beyond: pregnant women's views on the implications of an NIPT-based Down syndrome screening (six statements; see Table 1), categories of disorders for which pregnant women think NIPT-based screening should become available in the future (seven categories; see Figure 1), and pregnant women's views on the implications of NIPT for a broader range of conditions (six statements; see Table 2). Respondents were asked to indicate the extent to which they agreed with each statement or category on a 5 -point Likert scale $(1=$ completely disagree, 2 =disagree, $3=$ neither disagree, nor agree, $4=$ agree, and $5=$ completely agree).

To evaluate who should decide about the scope of NIPT, respondents were asked to answer the question: 'According to you, who should make the decision for which conditions NIPT becomes available?' (answer options: 'pregnant women and their partners'; 'healthcare professionals'; 'the government; patient or consumer organizations'; 'a special committee with a representative of all groups mentioned earlier'). Women were also asked by which method a broad range of conditions should be offered. Three options were listed: (1) 'closed offer': having NIPT means having the fetus tested for all disorders included in the offer; (2) 'optional packages': the offer of disorders is divided into categories, containing disorders similar in type and severity; the woman can choose for which category or categories she 
Table 1 Attitudes of pregnant women toward noninvasive prenatal testing-based Down syndrome screening

\begin{tabular}{|c|c|c|c|}
\hline Implementation of NIPT for Down syndrome leads to... & $\begin{array}{c}\text { (Completely) disagree } \\
n(\%)\end{array}$ & $\begin{array}{l}\text { Neither disagree nor agree } \\
\qquad n(\%)\end{array}$ & $\begin{array}{c}\text { (Completely) agree } \\
n(\%)\end{array}$ \\
\hline $\begin{array}{l}\text {...more pregnant women choosing to test for Down syndrome than with } \\
\text { the current screening test }\end{array}$ & $44(12)$ & $60(16)$ & $277(73)$ \\
\hline $\begin{array}{l}\text {...pregnant women thinking less comprehensively about participation in } \\
\text { prenatal screening than with the current screening test }\end{array}$ & $131(34)$ & $96(25)$ & $154(40)$ \\
\hline $\begin{array}{l}\text {...more pregnant women feeling obliged to participate in prenatal } \\
\text { screening than with the current screening test }\end{array}$ & $204(54)$ & $92(24)$ & $85(22)$ \\
\hline $\begin{array}{l}\text {... fewer children with Down syndrome being born than with the } \\
\text { current screening test }\end{array}$ & $95(25)$ & $132(35)$ & $154(40)$ \\
\hline $\begin{array}{l}\text {...prenatal screening being more useful for those who just want to } \\
\text { prepare for having a child with Down syndrome }\end{array}$ & $36(9)$ & $87(23)$ & $258(68)$ \\
\hline
\end{tabular}

NIPT, noninvasive prenatal testing.

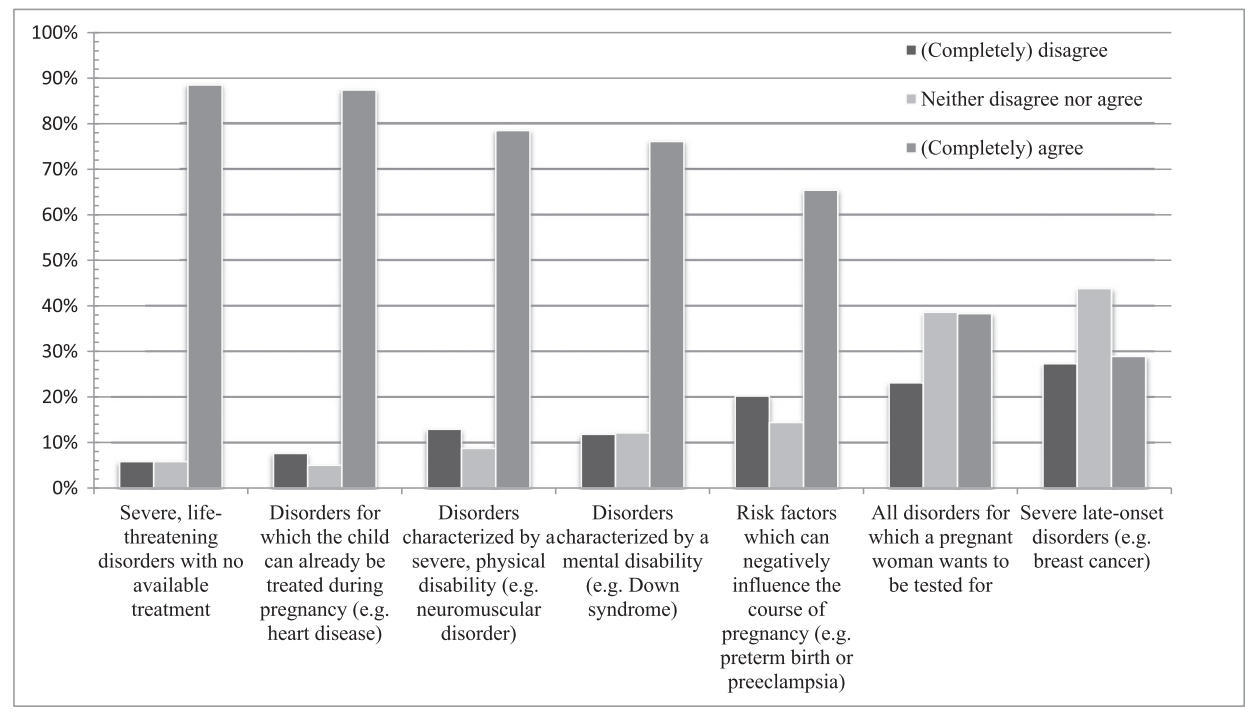

Figure 1 Level of agreement of pregnant women on testing for different categories of conditions with noninvasive prenatal testing

Table 2 Attitudes of pregnant women toward noninvasive prenatal testing for a broad range of conditions

\begin{tabular}{|c|c|c|c|}
\hline Testing with NIPT for a broad range of conditions... & $\begin{array}{c}\text { (Completely) disagree } \\
n(\%)\end{array}$ & $\begin{array}{l}\text { Neither disagree nor agree } \\
\qquad n(\%)\end{array}$ & $\begin{array}{c}\text { (Completely) agree } \\
n(\%)\end{array}$ \\
\hline .... is a good idea because it will avoid much suffering & $39(10)$ & $53(14)$ & $289(76)$ \\
\hline ...will lead to less acceptance of giving birth to an affected child & $157(41)$ & $86(23)$ & $138(36)$ \\
\hline ...will lead to less attention and care for people with a disorder & $236(62)$ & $85(22)$ & $60(16)$ \\
\hline ....should only be possible for disorders, so not for gender & $73(19)$ & $102(54)$ & $206(27)$ \\
\hline $\begin{array}{l}\text {...should also be possible for nonmedical cosmetic traits } \\
\text { (e.g. eye or hair color) }\end{array}$ & $333(87)$ & $29(8)$ & $19(5)$ \\
\hline $\begin{array}{l}\text {... will confront couples with choices, the implications of which } \\
\text { would be difficult for them to grasp }\end{array}$ & $107(28)$ & $126(33)$ & $148(39)$ \\
\hline
\end{tabular}

NIPT, noninvasive prenatal testing.

wants to have testing; and (3) 'free choice': the woman can choose herself which disorders in the offer the fetus is and is not tested for.
Finally, the questionnaire contained questions on sociodemographics, including age, level of education, ethnicity, religion, gestational age, and having children. 


\section{Data analysis}

Descriptive analyses were used to describe the characteristics of the respondents. To define pregnant women's interest in having NIPT, 'most certainly yes' and 'probably yes' were combined as well as 'most certainly not' and 'probably not'. The 5-point Likert scale used to measure agreement on the items shown in Tables 1 and 2 was compressed into a 3-point scale in order to avoid small cell sizes: (1) completely disagree or disagree, (2) neither disagree nor agree, and (3) agree or completely agree. Data were analyzed using SPSS 20.0 (IBM SPSS Statistics for Windows).

\section{RESULTS}

\section{Sample characteristics}

In total, 491 women participated in the online questionnaire; 24 women were not pregnant and therefore excluded. Women who did not complete the questions about NIPT $(n=58)$ or sociodemographic status $(n=28)$ were also excluded from analysis. Consequently, 381 questionnaires were included in the analysis. Respondents' characteristics are presented in Table 3.

Overall, the sample consisted of mostly highly educated women $(57 \%)$. The mean age was 28.8 years $(S D=4.3$, range: 18-40 years), and the mean gestational age was 18.7 weeks ( $S D=8.6$, range: $5-42$ weeks). Of the women, $27 \%$ reported that they had had first-trimester screening in the current or a previous pregnancy, and $10 \%$ mentioned that they were planning to do so.

\section{Views on NIPT-based Down syndrome screening}

Of the 381 respondents, the majority (61\%) had already heard of NIPT. Half of the respondents $(51 \%)$ indicated that they would want to have NIPT in this or their next pregnancy if NIPT was available, $23 \%$ were unsure, and $26 \%$ did not want to have NIPT. Of the women who did not want to have NIPT, $70 \%$ mentioned that this was because they would never consider terminating their pregnancy. Of the women who reported having declined first-trimester screening (63\%, $n=240), 33 \%$ said that they would choose for NIPT. Most women (56\%) were willing to pay $€ 150,30 \%$ were willing to pay nothing, and $14 \%$ were willing to pay more than $€ 250$.

Women's attitudes toward NIPT for Down syndrome are shown in Table 1 . The majority of women (73\%) agreed with the statement that implementation of NIPT as a replacement of the current first-trimester screening test would lead to a higher uptake of prenatal screening for Down syndrome. Of all respondents, $40 \%$ worried about 'routinization' of screening as they agreed that, with NIPT, women would think less comprehensively about participation in prenatal screening. An equal number of women $(40 \%)$ thought that because of NIPT, fewer children with Down syndrome would be born. On the other hand, $54 \%$ of women did not think that NIPT would lead to more women feeling obliged to participate in prenatal screening. The majority $(68 \%)$ of women thought that prenatal screening would become more meaningful as an
Table 3 Characteristics of respondents

\begin{tabular}{|c|c|}
\hline Characteristics & $\begin{array}{l}N=381 \\
n(\%)\end{array}$ \\
\hline \multicolumn{2}{|l|}{ Age (years) } \\
\hline$\leq 25$ & $82(22)$ \\
\hline $26-35$ & $275(72)$ \\
\hline$\geq 36$ & $24(6)$ \\
\hline \multicolumn{2}{|l|}{ Level of education ${ }^{a}$} \\
\hline Low/intermediate & $164(43)$ \\
\hline High & $217(57)$ \\
\hline \multicolumn{2}{|l|}{ Ethnicity $^{b}$} \\
\hline Dutch & $320(84)$ \\
\hline Other Western & $22(6)$ \\
\hline Non-Western & $36(9)$ \\
\hline Missing & $3(1)$ \\
\hline \multicolumn{2}{|l|}{ Religion $^{c}$} \\
\hline None & $223(59)$ \\
\hline Christian & $137(36)$ \\
\hline Muslim & $14(4)$ \\
\hline Other & $7(2)$ \\
\hline \multicolumn{2}{|l|}{ Level of religiousness } \\
\hline (Somewhat) active & $84(22)$ \\
\hline Not active/not religious & $297(78)$ \\
\hline \multicolumn{2}{|l|}{ Weeks of gestation } \\
\hline$\leq 13$ & $121(32)$ \\
\hline $14-27$ & $200(53)$ \\
\hline $28-42$ & $60(16)$ \\
\hline \multicolumn{2}{|c|}{ Experience with first-trimester screening ${ }^{d}$} \\
\hline No & $274(72)$ \\
\hline Yes & $107(27)$ \\
\hline \multicolumn{2}{|l|}{ Having children } \\
\hline No & $254(67)$ \\
\hline Yes & $127(33)$ \\
\hline
\end{tabular}

aow: elementary school, lower level of secondary school, and lower vocational training; intermediate: higher level of secondary school and intermediate vocational training; high: high vocational training and university. ${ }^{33}$

bEthnicity was categorized as Dutch, Other Western, or Non-Western by the following algorithm: Dutch if both parents were born in the Netherlands; Other Western if at least one of their parents was born in Europe (excluding Turkey), North America, Oceania, Indonesia, or Japan; and non-Western if at least one of their parents was born in Africa, Latin America, Asia (excluding Indonesia and Japan), and Turkey. If both parents were born abroad, then ethnicity was determined by the country of birth of the mother. ${ }^{33}$

${ }^{c}$ Christian: Calvinism, Protestantism, Roman Catholic, Reformed, and Baptism. Other: for example, Hinduism, Buddhism, and Paganism.

${ }^{\mathrm{d}}$ Nine respondents (also) had experience with invasive testing (chorionic villus sampling or amniocentesis)

option for couples who just want to be able to prepare themselves in case of a child with Down syndrome.

Views on a broader scope NIPT and its possible consequences Women were asked to indicate for which conditions NIPTbased screening should be made available (Figure 1). The 
majority of women agreed that this screening should test for life-threatening disorders (89\%), disorders characterized by severe physical disability (e.g. neuromuscular disorder) (79\%), and disorders characterized by severe mental disability (e.g. Down syndrome) (76\%). Moreover, $87 \%$ of women agreed that testing for fetal disorders treatable during pregnancy should be offered. Of the women, $65 \%$ stated that screening should be made available to identify risk factors with a negative influence on the course of pregnancy, such as preeclampsia or preterm birth, while only $29 \%$ of the women agreed that screening for late-onset disorders, such as hereditary breast cancer, should be made available. Of the respondents, $38 \%$ agreed that NIPT-based screening should be made available for any disorders a woman wants to test for, although an equal percentage of women neither agreed nor disagreed with this.

The attitudes of women toward screening for a broad range of conditions with NIPT are shown in Table 2. The majority of women $(76 \%)$ agreed that testing for a broad range of conditions is a good idea as it could avoid much suffering, and $62 \%$ did not think that this would lead to less attention and care being given to people with a disorder. In contrast, $36 \%$ thought that it would lead to less acceptance of giving birth to an affected child. Moreover, 39\% of the women thought that screening for a broad range of conditions would confront couples with choices, the implications of which are difficult for them to comprehend. The statement that screening should be made available for nonmedical cosmetic traits, like eye or hair color, was rejected by the vast majority of women $(87 \%)$. Regarding testing for gender, however, most women (54\%) neither agreed nor disagreed, while only $19 \%$ agreed that it should be made available.

\section{A broader scope for NIPT: deciding what becomes available and} how it is offered

Of the women, $40 \%$ felt that the decision for what kind of conditions NIPT-based screening may be offered should be made by pregnant women (and their partners), while 31\% felt that this should be the responsibility of a special commission including delegates from the government, healthcare professionals, patient organizations, and pregnant women. Of the women, $23 \%$ stated that the decision should be made by healthcare professionals, and only $2 \%$ of the women felt that the government or the patient-consumer organizations should be making this decision.

The largest group of respondents $(41 \%)$ thought that testing for a broad range of conditions should be offered as a 'free choice'. About a third (31\%) felt that it should be offered as a 'closed offer', and a slightly lower percentage (26\%) felt that it should be offered in 'optional packages'.

\section{DISCUSSION}

Half of the women in this study expressed interest in having NIPT, including a third of women who reported having declined first-trimester screening. The majority of women thought that the uptake of screening would increase with NIPT. Testing for a broader range of conditions could avoid much suffering, according to women. A considerable number of women thought that choices should be individualized with regard to the disorders for which the fetus gets tested. Nonetheless, $39 \%$ of the women feared that if NIPT is offered for a broader range of conditions, couples will be faced with choices, the implications of which are difficult for them to comprehend.

\section{Views on NIPT-based Down syndrome screening}

A relatively large percentage of respondents in this study had already heard of NIPT even though the test was not yet available. This can most likely be attributed to a widespread media coverage following a year of debate about NIPT and the government's announcement that it was going to be available soon. The majority of the women thought that with NIPT, the uptake of prenatal screening would increase. Earlier studies among pregnant women (and partners) in the $\mathrm{UK}^{4}$ and the Netherlands ${ }^{4,18}$ also concluded that implementing NIPT may result in a higher uptake of screening. However, interest in having NIPT in our study $(51 \%)$ was not nearly as high as found in other studies, where hypothetical interest reached $72 \%^{3}$ and even $88 \% .{ }^{4}$ Interestingly, now that NIPT is actually being offered to women, the uptake of NIPT seems to be lower, ${ }^{19,20}$ although this could partly be due to the fact that it is still an expensive test that is not always reimbursed. Most women were willing to pay $€ 150$ for NIPT (the same amount as for the first-trimester screening), similar as to what was found by another Dutch study. ${ }^{2}$

The majority of respondents felt that with NIPT, prenatal screening would become more useful for those who just want to be informed in order to prepare themselves in case of Down syndrome. This is in line with studies by Lewis et al. ${ }^{4}$ and Verweij et al., ${ }^{18}$ who found that a significant group who reported to choose for NIPT would not terminate their pregnancy. Moreover, a study in the UK concluded that although women had a positive attitude toward prenatal testing for most of the genetic conditions presented, their attitudes toward termination of pregnancy for these conditions were much less positive. ${ }^{21}$ These findings suggest that the expected higher uptake of NIPT need not result in a corresponding increase in termination of pregnancies.

A large percentage of women in this study worried that women might feel a reduced need to reflect on the pros and cons of prenatal screening with NIPT. This concern about a possible 'routinization' of prenatal screening as a result of the ease and safety of NIPT was also expressed by pregnant women in our previous qualitative study. ${ }^{6}$ Similar concerns are raised in the literature with regard to professional attitudes about the need for providing more than rudimentary pretest information about NIPT. ${ }^{22}$

Views on a broader scope NIPT and its possible consequences Most women agreed that testing for life-threatening, severe physical, or severe mental disorders should be offered. Fewer women $(65 \%)$ felt that screening should include testing for risk factors that can negatively influence the course of pregnancy, such as preeclampsia or preterm birth. This is remarkable, as one would expect more women to agree with this, because it could benefit the health of both the woman and her child. ${ }^{12}$ 
The reason why fewer women in this study support this type of screening is not clear, but it could be that respondents did not fully understand this concept, as this kind of testing is not yet performed in the current practice and limited information was given.

Almost a third of respondents agreed to testing for severe late-onset disorders, like hereditary breast cancer. Testing for late-onset disorders in pregnancy is much debated mostly because, in the case of a continuing pregnancy, the child will be born with possibly 'undesirable' information, depriving him or her of the 'right not to know' and potentially leading to psychosocial harm. ${ }^{23-25}$ Another type of controversial testing, namely testing for nonmedical cosmetic traits or gender, was also seen as unacceptable to most of the women in this study. This is in line with earlier studies on women's attitudes $^{6,26}$ and also corresponds to the view of many professionals that sex selection for nonmedical reasons is to be rejected. ${ }^{27}$

Although most women thought that NIPT-based screening for a broad range of conditions would avoid much suffering and would not lead to less care for people with a disorder, a considerable number feared that it would lead to less acceptance of giving birth to an affected child. The latter is in line with findings from a UK study among the general public, showing fear for a societal quest for 'perfection' and a lack of tolerance for people with a disability when the use of NIPT gets expanded. ${ }^{28}$

\section{A broader scope NIPT: deciding what becomes available and how it is offered}

In this study, a significant number of women thought that NIPT should be allowed for any disorder a woman wants to test for. Moreover, when being offered NIPT, a slight majority of women wanted the option to have a 'free choice' from a list of disorders, instead of a 'closed offer' or an offer in 'optional packages'. In this study, we thus found some support for the notion that when offered NIPT-based prenatal screening, women or couples should be allowed to make an individualized choice with regard to the range of conditions for which they would want to have the fetus tested. However, respondents seemed aware that testing for a broad range of conditions may complicate the decision-making process beyond what most couples are able to comprehend. This was also found in a study by De Jong et al., ${ }^{15}$ where participants favored an individualized choice about the scope of the test but realized this would be so complex that it could overburden women. These worries are conceivable, as offering a broader scope test would require more elaborate and detailed information about the specifics of all conditions included in the offer, complicating the counseling process. ${ }^{29}$ Hewison et $a .^{30}$ show that women hold different opinions about the conditions that to them merit prenatal testing, and it was argued that individual views should be respected in order to achieve informed consent. They also acknowledged, though, that this is particularly difficult when offering a test for a broad range of conditions because of the risk of 'information overload'. ${ }^{30}$ Interestingly, the 'optional packages' approach that is proposed in the literature as a way to solve this problem while allowing couples to make their own reproductive decisions as much as possible ${ }^{31}$ received the least support in our study.

\section{Strengths and limitations}

One of the strengths of this study was the relatively large sample size and the fact that we included both women who already had experience with prenatal screening and women who had not. Our sample was also representative of the general population of pregnant women in the Netherlands regarding the average age at which they had their first child and uptake of Down syndrome screening. ${ }^{16}$ However, the sample consisted of mostly highly educated, Dutch Caucasian women, which makes it less generalizable. Also, the survey measured intention to have NIPT, which is known to not always correspond well with the actual uptake of screening, as we have seen with the first-trimester screening test. ${ }^{32}$ Finally, this study only addresses public attitudes in the Netherlands, which is a country with a relatively low uptake of prenatal screening. Therefore, results cannot be seen as being representative of other countries, but many similarities are evident.

\section{CONCLUSION}

The findings of this study suggest that the introduction of NIPT as a first screening test will result in an increase in the uptake of prenatal screening in the Netherlands. When, in the future, NIPT-based prenatal screening can be offered for a broader range of conditions, it is important to further investigate how to offer such a test in a way that strikes a careful balance between imposing unjustified limits to individualized choice, on the one hand, and overburdening women's capacities for autonomous decision-making on the other hand.

\section{ACKNOWLEDGEMENTS}

The authors wish to thank the women who participated in the study. The Dutch 'Nine Months Fair' (Negenmaandenbeurs) is acknowledged for placing the link to the questionnaire on their website.

\section{WHAT'S ALREADY KNOWN ABOUT THIS TOPIC?}

- Studies have shown positive attitudes toward noninvasive prenatal testing (NIPT), although some concerns have been expressed about its use.

\section{WHAT DOES THIS STUDY ADD?}

- Most women believe that a broad-range NIPT-based screening would prevent suffering and should include life-threatening, severe physical, and severe mental disorders. A minority supports screening for nonmedical traits, gender, and late-onset disorders

- Support for individualized choice, as well as fear that a broadrange NIPT-based screening would confront couples with choices, the implications of which would be difficult to grasp, was found. 


\section{REFERENCES}

1. Lo YMD. Non-invasive prenatal diagnosis by massively parallel sequencing of maternal plasma DNA. Open Biol 2012;2(6).

2. Verweij EJ, Oepkes D, De Vries M, et al. Non-invasive prenatal screening for trisomy 21: what women want and are willing to pay. Patient Educ Couns 2013;93:641-5.

3. Tischler R, Hudgins L, Blumenfeld YJ, et al. Noninvasive prenatal diagnosis: pregnant women's interest and expected uptake. Prenat Diagn 2011;31:1292-9.

4. Lewis C, Hill M, Silcock C, et al. Non-invasive prenatal testing for trisomy 21: a cross-sectional survey of service users' views and likely uptake. BJOG: Int J Obstet Gynecol 2014;121:582-94.

5. Lewis C, Silcock C, Chitty LS. Non-invasive prenatal testing for Down's syndrome: pregnant women's views and likely uptake. Public Health Genomics 2013;16:223-32.

6. van Schendel RV, Kleinveld JH, Dondorp WJ, et al. Attitudes of pregnant women and male partners towards non-invasive prenatal testing and widening the scope of prenatal screening. Eur J Hum Genet 2014;22:1345-50.

7. Avent ND, Madgett TE, Maddocks DG, Soothill PW. Cell-free fetal DNA in the maternal serum and plasma: current and evolving applications. Curr Opin Obstet Gynecol 2009;21:175-9.

8. Lo YM, Chan KC, Sun H, et al. Maternal plasma DNA sequencing reveals the genome-wide genetic and mutational profile of the fetus. Sci Transl Med 2010;2:61ra91.

9. Kitzman JO, Snyder MW, Ventura M, et al. Noninvasive whole-genome sequencing of a human fetus. Sci Transl Med 2012;4:137ra76.

10. Chitty LS, Griffin DR, Meaney C, et al. New aids for the non-invasive prenatal diagnosis of achondroplasia: dysmorphic features, charts of fetal size and molecular confirmation using cell-free fetal DNA in maternal plasma. Ultrasound Obstet Gynecol 2011;37:283-9.

11. Vora NL, O'Brien BM. Noninvasive prenatal testing for microdeletion syndromes and expanded trisomies: proceed with caution. Obstet Gynecol 2014;123:1097-9.

12. Van Dijk M, Visser A, Posthuma J, et al. Naturally occurring variation in trophoblast invasion as a source of novel (epigenetic) biomarkers. Front Genet 2012;3:22.

13. Van der Steen SL, Diderich KEM, Riedijk SR, et al. Pregnant couples at increased risk for common aneuploidies choose maximal information from invasive genetic testing. Clin Genet 2014:Epub ahead of print.

14. Farrell RM, Agatisa PK, Nutter B. What women want: lead considerations for current and future applications of noninvasive prenatal testing in prenatal care. Birth 2014;41:276-82.

15. De Jong A, Dondorp W, Krumeich A, et al. The scope of prenatal diagnosis for women at increased risk for aneuploidies: views and preferences of professionals and potential users. J Community Genet 2013;4:125-35.

16. Schielen P. Quality control parameters of Dutch Down's syndrome screening laboratories 2010. RIVM; 2010. Report No.: 230083003/2012.
17. TRIDENT 2014. Trial by Dutch laboratories for evaluation of noninvasive prenatal testing (NIPT). URL http://www.emgo.nl/research/ quality-of-care/research-projects/1451/trident-study-trial-by-dutchlaboratories-for-evaluation-of-non-invasive-prenatal-testing-nipt/ background/ [accessed on 10 December 2014].

18. Verweij EJ, Oepkes D, de Boer MA. Changing attitudes towards termination of pregnancy for trisomy 21 with non-invasive prenatal trisomy testing: a population-based study in Dutch pregnant women. Prenat Diagn 2013;33:397-9.

19. Taylor J, Chock V, Hudgins L. NIPT in a clinical setting: an analysis of uptake in the first months of clinical availability. J Genet Counsel 2014;23:72-8.

20. Chetty S, Garabedian MJ, Norton ME. Uptake of noninvasive prenatal testing (NIPT) in women following positive aneuploidy screening. Prenat Diagn 2013;33:542-6.

21. Alsulaiman A, Hewison J, Abu-Amero KK, et al. Attitudes to prenatal diagnosis and termination of pregnancy for 30 conditions among women in Saudi Arabia and the UK. Prenat Diagn 2012;32:1109-13.

22. Van den Heuvel A, Chitty L, Dormandy E, et al. Will the introduction of non-invasive prenatal diagnostic testing erode informed choices? An experimental study of health care professionals. Patient Educ Couns 2010;78:24-8.

23. Dondorp W, Sikkema-Raddatz B, De Die-Smulders C, De Wert G. Arrays in postnatal and prenatal diagnosis: an exploration of the ethics of consent. Hum Mutat 2012;33:916-22.

24. Bredenoord AL, De Vries MC, Van Delden JJM. Next-generation sequencing: does the next generation still have a right to an open future? Nat Rev Genet 2013;14:306.

25. Donley G, Hull SC, Berkman BE. Prenatal whole genome sequencing. Hastings Cent Rep 2012;42:28-40.

26. Farrimond HR, Kelly SE. Public viewpoints on new non-invasive prenatal genetic tests. Publ Understand Sci 2013;22:730-44.

27. Soini S, Ibarreta D, Anastasiadou V, et al. The interface between assisted reproductive technologies and genetics: technical, social, ethical and legal issues. Eur J Hum Genet 2006;14:588-645.

28. Kelly SE, Farrimond HR. Non-invasive prenatal genetic testing: a study of public attitudes. Public Health Genomics 2011;15:73-81.

29. De Jong A, Dondorp WJ, De Die-Smulders CEM, et al. Non-invasive prenatal testing: ethical issues explored. Eur J Hum Genet 2009;18:272-7.

30. Hewison J, Green JM, Ahmed S, et al. Attitudes to prenatal testing and termination of pregnancy for fetal abnormality: a comparison of White and Pakistani women in the UK. Prenat Diagn 2007;27:419-30.

31. De Jong A, Dondorp WJ, Frints SGM, et al. Advances in prenatal screening: the ethical dimension. Nat Rev Genet 2011;12:657-63.

32. Bakker M, Birnie E, Pajkrt E, et al. Low uptake of the combined test in the Netherlands—which factors contribute? Prenat Diagn 2012;32:1305-12.

33. Statistics Netherlands. [WWW document]. URL http://www.cbs.nl/ nl-NL/menu/home/default.htm [accessed on 10 November 2014]. 